\title{
Prevalence of "organic brain syndrome" in a Southern European population in two different time periods. The ZARADEMP Project
}

\author{
Antonio Lobo, MD* \\ Pedro Saz, MD* \\ Guillermo Marcos, MD** \\ José-Luis Día, MD*** \\ Concepción De-la-Cámara, MD* \\ Tirso Ventura, MD*** \\ José Ángel Montañés, MD* \\ Antonio Lobo-Escolar, MD* \\ Sergio Aznar, MD* \\ ZARADEMP Workgroup
}

* Servicio de Psiquiatría and Departamento de Medicina y Psiquiatría, Facultad de Medicina of the Universidad de Zaragoza and Hospital Clínico Universitario

** Departamento de Medicina Preventiva y Salud Pública, Facultad de Medicina of the Universidad de Zaragoza and Hospital Clínico Universitario

*** Servicio de Psiquiatría, Hospital Universitario Miguel Servet. Zaragoza

SPAIN

\footnotetext{
ABSTRACT - Background: Comparative studies of dementia in different time periods are quite limited in the international literature, but might be useful to test environmental hypotheses. The aim of this study is to compare the prevalence of "organic brain syndrome", as a measure of dementia, in the elderly living in the same community in two different time periods and using the same methods.

Methods: Representative samples of the elderly in the Zaragoza Study or ZARADEMP $O(\mathrm{n}=1,080)$, completed the past decade, and now in Wave I of the ZARADEMP Project or ZARADEMP I $(\mathrm{n}=4,803)$ were interviewed. The Geriatric Mental State (GMS) was the main case-finding instrument and the results were analysed using the AGECAT diagnostic package to generate diagnoses.

Results: Adjusted, total prevalence of "organic brain syndrome" in individuals aged 65 years and older has not varied from the previous decade. It was $8.4 \%$ in ZARADEMP I , and $7.4 \%$ in ZARADEMP $O$ (prevalence ratio, $\mathrm{PR}=0.83$; CI 0.65-1.07). Adjusted preva-
} 
lence among men was lower in ZARADEMP I (3.6\%) when compared to ZARADEMP 0 $(5.5 \%)$, although the differences do not reach statistically significance ( $P R=0.65$; CI 0.411.05). However, in support of the working hypothesis, the differences were more marked, and we consider they reach statistically significant proportions in the age group $80-84$ years.

Conclusions: The prevalence of "organic brain syndrome" has not increased from the previous decade. On the contrary, the prevalence tends to be lower in men, and the differences reach stastistical significance in the age group 80-84 years. New analysis using diagnostic criteria of dementia in the same sample are required to confirm these findings.

\section{Introduction}

A similarity of the overall prevalence estimates of dementia in different countries has been reported when only studies using similar methods were compared, such as in the EURODEM reports (Hofman et al. 1991, Lobo et al. 2000). The similarity of estimates was also apparent in a cross-cultural comparison conducted the previous decade between the cities of Liverpool and Zaragoza (Zaragoza Study or ZARADEMP $0)$ when the Geriatric Mental State (GMS) AGECAT criteria of "organic brain syndrome" were used as a measure of dementia (Lobo et al. 1992). However, epidemiological conjectures were stimulated in both EURODEM reports, which included preliminary data from Zaragoza, by the appearance of some disparities in rates of dementia among men. Furthermore, contrary to most epidemiological enquiries, in ZARADEMP $O$ we found a relative increase in the prevalence of dementia (DSM-III-R criteria, American Psychiatric Association, 1987) in men when compared to women, particularly in the age groups between 70 years and 84 years (Lobo et al. 1995).

Comparative studies in different time periods, which are quite limited in the inter- national literature (Kokmen et al. 1993), might also test environmental hypotheses. Since we have conducted during the ZARADEMP Project, as described in a previous paper (Lobo et al. 2005a), a reappraisal of the age and sex distribution of dementia in the same city, we could compare the findings with data collected in the same city the previous decade and using the same methods. We now hypothesize that, compared to ZARADEMP 0 , a decreased prevalence of GMS-AGECAT "organic brain syndrome" in men will be found in ZARADEMP I, particularly in the age groups between 70 years and 84 years.

\section{Method}

Similar methods were used in both studies, but there were differences in the sampling frame due to the different objectives in both investigations. The background, objectives and general methodology of the ZARADEMP Project are described in previous articles (Lobo et al. 2005a, Lobo et al. 2005b). In brief, this is an epidemiological study with three waves, but only the results of Wave I (ZARADEMP I), the baseline, cross-sectional study will be used here. A 
random sample of individuals aged 55 and over, stratified by age and sex was drawn from municipal census lists (Spanish census, 1991). Ultimately 4,803 people were interviewed (years 1994-1996), but for comparative purposes in this study only the people aged 65 and over will be considered. The interviewers were senior medical students, and their training was carried out by one of the authors (A.L.) who had been trained in the use of the GMS in Liverpool (Lobo et al. 1992).

Similar methods were used in ZARADEMP 0 (Lobo et al. 1995). In brief, a random sample of individuals aged 65 and over, stratified by age and sex was drawn from municipal inhabitants lists. Ultimately 1,080 people were interviewed (years 19881989). The interviewers were also medical students having the same training than in the other study.

In both studies, all interviews were carried out using shortened community versions of the GMS schedule (Copeland $e t$ al. 1976). This instrument, of which a more detailed description is given in the methods paper, has been used extensively in epidemiological studies in English speaking, as well as non-English speaking countries. A careful process of translation and validation of the Spanish version of the GMS has previously been carried out. The results were analysed using the AGECAT computerized diagnostic package (Copeland et al. 1986), which is also described in the previous paper, to generate diagnoses. The authors have reported the validity of the Spanish version of AGECAT (Saz et al. 1996). AGECAT diagnostic cases of "organic brain syndrome" nominated by Stage II were used as a measure of dementia. The AGECAT diagnosis of "organic brain syndrome" has been shown (Copeland et al. 1990) to correspond to diagnoses of dementia made according to the rules of DSM-III-R (American Psychiatric Association, 1987).

\section{Results}

The age-sex distribution of the two samples is shown in Table I. The table also shows the prevalence of "organic brain syndrome" for each five-year age band for each gender, as well as the global prevalence data. The expected steep rise of prevalence with age in ZARADEMP I is seen, similarly to ZARADEMP 0, but the rise is more regular in the former. The total prevalence, adjusted by age in ZARADEMP I was $8.4 \%$ (CI 7.6-9.3) (Table I), and there were no significant differences with the previous study (prevalence ratio, $\mathrm{PR}=1.14$; CI 0.901.44) (Table II). For comparative purposes, in view of the progressive aging of city dwellers in Zaragoza and changes in the population structure over the last, approximately ten years, adjusted total prevalence has been calculated. It was $7.3 \%$ (CI 5.79.0) in ZARADEMP 0 and 6.1\% (CI 5.36.7), in ZARADEMP $I$, the differences being non-significant (Table II).

Contrary to the previous study, the prevalence of "organic brain syndrome" in ZARADEMP I was significantly higher in women (10.5\%, CI 9.2-11.8) when compared to men $(5.5 \%$, CI 4.3-6.6), PR = 1.92; CI 1.52-2.43) (Tables I and III), and the differences are also significant if total prevalence is adjusted by age (Tables I and III).

No significant differences in the prevalence of "organic brain syndrome" in women, total or adjusted, were observed between ZARADEMP $O$ and ZARADEMP I 
Table I

Prevalence of "organic brain syndrome" (AGECAT criteria), by sex and age, and study

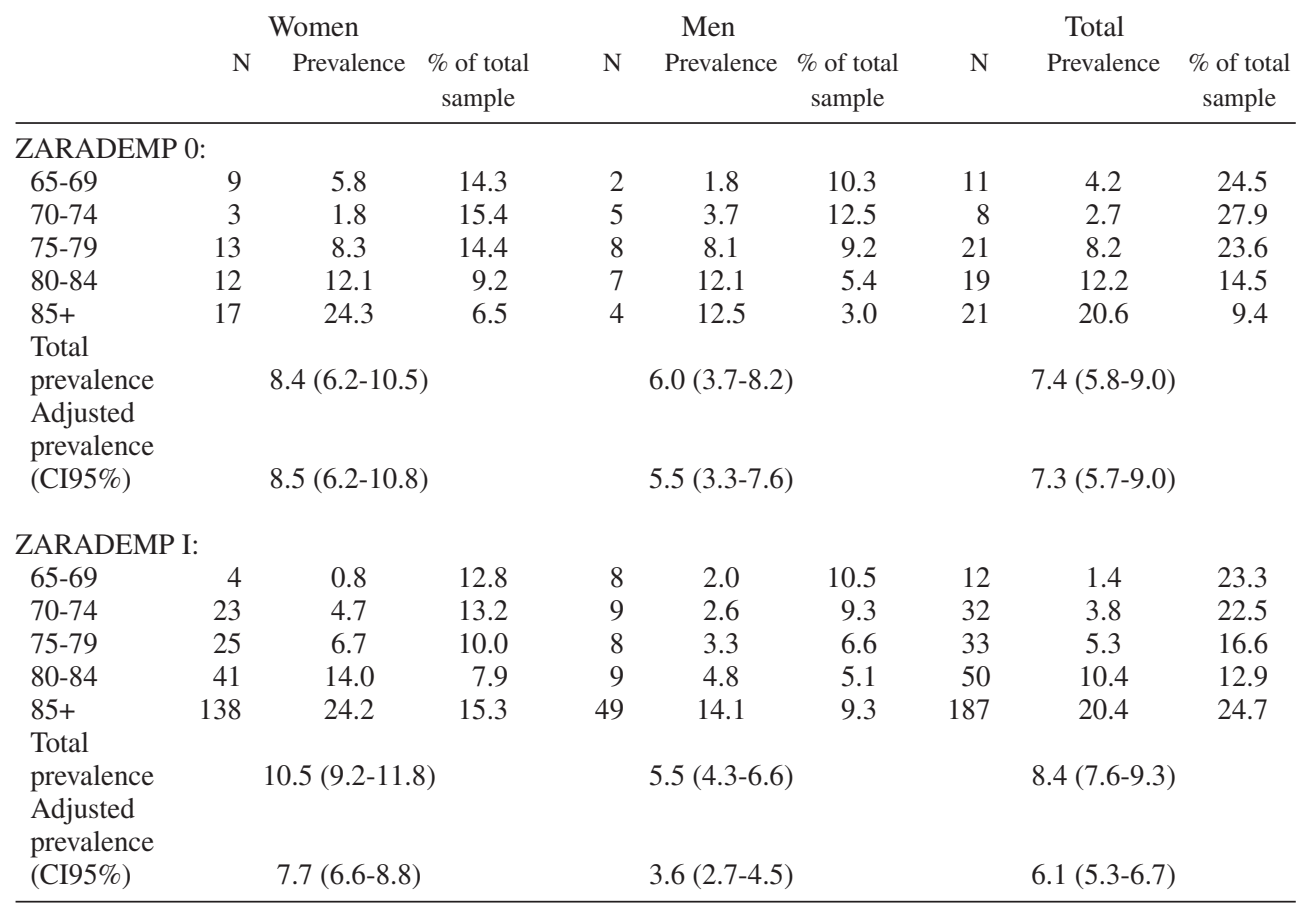

Table II

Prevalence Ratio (PR) of "organic brain syndrome”, ZARADEMP I vs. ZARADEMP 0, by sex and age

\begin{tabular}{lcccccc} 
& \multicolumn{2}{c}{ Women } & \multicolumn{2}{c}{ Men } & \multicolumn{2}{c}{ Total } \\
Age group & PR & CI 95\% & PR & CI 95\% & PR & CI 95\% \\
\hline $65-69$ & 0.14 & $0.05-0.39$ & 1.14 & $0.24-5.27$ & 0.33 & $0.15-0.72$ \\
$70-74$ & 2.59 & $0.83-8.06$ & 0.70 & $0.24-2.06$ & 1.44 & $0.67-3.07$ \\
$75-79$ & 0.81 & $0.42-1.54$ & 0.40 & $0.16-1.02$ & 0.65 & $0.38-1.10$ \\
$80-84$ & 1.16 & $0.64-2.11$ & 0.40 & $0.16-1.00$ & 0.86 & $0.52-1.42$ \\
$85+$ & 1.00 & $0.64-1.55$ & 1.13 & $0.44-2.91$ & 0.99 & $0.66-1.48$ \\
Total & 1.25 & $0.95-1.66$ & 0.92 & $0.60-1.41$ & 1.14 & $0.90-1.44$ \\
Adjusted & 0.91 & $0.68-1.21$ & 0.65 & $0.41-1.05$ & 0.83 & $0.65-1.07$ \\
\hline
\end{tabular}

Table III

Prevalence Ratio (PR) of dementia, women vs. men, by study

\begin{tabular}{lcc} 
Study & PR & CI 95\% \\
\hline ZARADEMP 0 & & \\
$\quad$ Total & 1.40 & $0.89-2.19$ \\
$\quad$ Adjusted* & 1.56 & $0.98-2.48$ \\
ZARADEMP I & 1.92 & $1.52-2.43$ \\
$\quad$ Total & 1.49 & $1.13-1.98$ \\
$\quad$ Adjusted* &
\end{tabular}

* Ratio of adjusted (by age) prevalence 
(Tables I and II). The prevalence among men in ZARADEMP I (5.5\%, CI 4.3-6.6) was lower than in the previous, $Z A$ RADEMP 0 study (6.0\%, CI 3.7-8.2) (Table I), but the differences were non significant (PR = 0.92 (CI 0.60-1.41) (Table II). Similarly, the between studies differences were non significant among men if prevalence data are adjusted by age: it was $3.6 \%$ (CI 2.7-4.5) in ZARADEMP I and 5.5\% (CI 3.37.6) in ZARADEMP O (Table I); $\mathrm{PR}=0.65$ (CI 0.41-1.05) (Table II) .

However, in support of the working hypothesis, the between studies differences of prevalence in men were more marked, and we believe they reach statistically significant proportions in the age group 80-84 years $(\mathrm{PR}=0.40$; CI 0.16-1.00) (Table II).

\section{Discussion}

\section{Prevalence of "organic brain syndrome"}

The final results of the baseline, cross sectional study in ZARADEMP I confirm in a large, representative community sample that a considerable proportion of the elderly community has an "organic brain syndrome" (prevalence 8.4\%, CI 7.6-9.3), a measure of dementia. (The overall prevalence in the ZARADEMP I sample, including the individuals below 65 years, was $6.7 \%$, CI 6.0-7.4). They also confirm the expected, steep rise of prevalence with age, which has been reported in dementia studies across Europe (Hofman et al. 1991, Lobo et al. 2000) and, in fact, unanimously in the international literature (Gallo and Lebowitz 1999).

\section{Prevalence rate of "organic brain syndrome" in two different time periods}

An important objective in this study was to compare the prevalence of "organic brain syndrome" involving two different periods of time in the same city and using the same methods. We are not aware of previous comparative studies of this kind, which might throw some light in view of beliefs in relation to the epidemic proportion of dementia (Plum 1979). Furthermore, comparative studies in different time periods also have the potential to test environmental hypotheses. While a follow-up study of hospital cases done in Minnesota suggested an increase in the relative incidence of DAT (Kokmen et al. 1993), the issue needs further exploration. The results of this study suggest that prevalence rates are similar in ZARADEMP $O$ and ZARADEMP I and, therefore, the prevalence of "organic brain syndrome", a measure of dementia has not increased in a period of approximately seven years.

However, the main objective of this report was related to our previous observation in ZARADEMP 0 of a relative, non-significant increase of the prevalence of dementia in men compared to women, when using DSM-III-R diagnostic criteria (Lobo et al. 1995). This relative increase of prevalence in men was observed in all age groups until the age of 90 years, and the finding is contrary to most reports in the literature (Jorm et al. 1987, Hofman et al. 1991). While the final results of $Z A$ RADEMP 0 when using AGECAT diagnostic criteria reported now do not confirm this relative increase of "organic brain syndrome" in men, the issue merits some further examination in view of the different criteria used and the limited number of 
cases in some age subgroups. Our results tend to confirm the hypothesis that, compared to ZARADEMP 0 , a decreased prevalence in men would be found in ZARADEMP I, particularly in some age sub-groups. First, contrary to ZARADEMP $O$, the prevalence of dementia in women in ZARADEMP I is significantly higher than in men. Second, contrary to the observation in women, the total prevalence in men was higher in ZARADEMP $O$ in relation to ZARADEMP I, although the differences were not statistically significant. And third, a higher prevalence of dementia in men was seen in all age groups between the ages of 70 and 84 years in ZARADEMP 0 , when compared to ZARADEMP I, and we take these differences as being statistically significant in the age group 80-84 years.

The two time points for comparison between samples are too close together to detect differences in exposure in this particular study, but the relative increase in the prevalence of dementia found in men in ZARADEMP 0 merits some discussion. Environmental influences have been suggested in cross-national studies reporting more differences among men than among women on the prevalence of both, global dementia and DAT (Hofman et al. 1991, Rocca et al. 1991). Geographical differences in these studies might also be influenced by factors such as the rate of institutionalization or survival in different countries, but this potential bias is not influencing our comparative study, completed in the same city. Furthermore, the potential educational bias is minimized here, since the case-finding instruments used had been standardized in this specific, Spanish elderly population, and the proportion of the elderly with limited education (primary, complete or incomplete) was similar in ZARADEMP $O(82.8 \%)$ and
ZARADEMP I (83.8\%). Other environmental factors could be considered, such as childhood exposure to infectious agents (Pyles 2001); higher smoking or toxin exposure during adulthood (Suay and Ballester 2002, Juan et al. 2004); or dietary deprivation at some point in the development (Esposito et al. 2002). However, men in the age groups with higher than expected prevalence of "organic brain syndrome" in ZARADEMP 0 were in military age during the Spanish civil war. Important demographic movements related to that period of time have been documented, as well as adverse social outcomes (Cabré and Pérez 2004). Cognitive impairment has been associated in some studies to both, social disengagement (Bassuk et al. 1999) and, in particular, to stress related to the war (Sutker et al. 1990). These hypotheses must be tested in new analysis of the prevalence of dementia using DSM criteria, since "organic brain syndrome" is not equivalent to dementia. In particular, the hypotheses must be tested on incidence data in this same ZARADEMP Project, since prevalence studies are not adequate to study risk factors.

\section{Other limitations of the study}

Both studies in the same city, in this comparative report, fulfil present day requirements in psychiatric epidemiology, such as the investigation of representative community samples which include institutionalized and non-institutionalized elderly, standardized structured methods of assessment specifically developed for the elderly and standardized diagnostic criteria and case levels of illness (Kaelber and Regier 1995, Copeland et al. 1999). Among the limitations of the study, it may be argued that the sampling methods are not totally 
comparable, since ZARADEMP 0 used random sampling with replacement. On the contrary, ZARADEMP I used a random sample, with size corrected for potential losses. However, the response rate was similar in both studies, and in ZARADEMP 0 no differences of prevalence were observed between the full sample interviewed and the sample selected as the first choice (Lobo et al. 1995). Therefore, we feel the results are broadly comparable. Other limitations in ZARADEMP I could be related to higher non-response rate due to refusals in women (Lobo et al. 2005b). Underestimation of prevalence rates of dementia might occur, since most studies have reported higher epidemiological rates of dementia among women (Copeland et al. 1999, Andersen et al. 1999). However, this potential underestimation would be limited and should not affect the main conclusions of the study, which are related to comparisons of prevalence rate of "organic brain syndrome" in men.

\section{Acknowledegements}

Supported by grants 94-1562, 97-1321E, 98-0103 and 01-0255 from the Fondo de Investigación Sanitaria, Ministerio de Sanidad, Madrid, Spain, by grant CICYT SAF93-0453 from the Dirección General de Investigación científica y Técnica, Secretaría General de Universidades, Madrid, and by grants from the Fundación CAI and Fundación Pfizer.

The authors acknowledge the contribution of the members of the team, psychiatrists and medical students, who participated in the field study as lay interviewers. We also thank Robert Robinson, at the Department of Psychiatry, Iowa University, USA, and John RM Copeland, at the Department of Psychiatry, University of Liverpool, United Kingdom, for their encouragement and helpful criticisms of the final draft of this article.

\section{References}

American Psychiatric Association. Diagnostic and statistical manual of mental disorders ( $3^{\text {rd }}$ Rev. Edition) (DSM IIII-R). Washington DC:American Psychiatric Press; 1987.

American Psychiatric Association. Diagnostic and statistical manual of mental disorders (4 $4^{\text {th }}$ ed.) (DSM-IV). Washington DC: American Psychiatric Press; 1994.

Andersen K., Launer LJ, Dewey ME, et al. Gender differences in the incidence of $\mathrm{AD}$ and vascular dementia: The EURODEM Studies. EURODEM Incidence Research Group. Neurology 1999; 53(9): 1992-1997.

Bassuk SS, Glass TA, Berkman LF. Social disengagement and incident cognitive decline in the communitydwelling elderly persons. Ann Intern Med 1999; 131(3): 165-173.

Cabre i Pla A, Pérez J. Envejecimiento demográfico en España. [monograph on the Internet].(Date of access: december 2004). Available from URL: http://www.ced. uab.es/jperez/pdfs/seniors.pdf.

Copeland JR, Dewey ME, Griffiths-Jones HM. A computerized psychiatric diagnostic system and case nomenclature for elderly subjects: GMS and AGECAT. Psychol Med 1986; 16(1): 89-99.

Copeland RM, Dewey ME, Griffiths-Jones HM. Dementia and depression in elderly persons: AGECAT compared with DSM-III and pervasive illness. Int J Geriatr Psych 1990; 5: 47-51.

Copeland JRM, Kelleher MJ, Kellett JM, et al. A semistructured clinical interview for the assessment of diagnosis and mental state in the elderly: the Geriatric Mental State Schedule. I. Development and reliability. Psychol Med 1976; 6: 39-449.

Copeland JRM, McCracken CF, Dewey ME, et al. Undifferentiated dementia, Alzheimer's disease and vascular dementia: age- and gender-related incidence in Liverpool. The MRC-ALPHA Study. Brit J Psychiat 1999; 175: 433-438.

Esposito E, Rotilio D, Di Matteo V, et al. A review of specific dietary antioxidants and the effects on biochemical 
mechanisms related to neurodegenerative processes. $\mathrm{Neu}$ robiol Aging 2002; 23(5): 719-735.

Gallo JJ, Lebowitz BD. The epidemiology of common late-life mental disorders in the community: themes for the new century. Psychiat Serv 1999; 50: 1158-1166.

Hofman A, Rocca WA, Brayne C, et al.The prevalence of dementia in Europe. A collaborative study of 1980-1990 prevalence findings. Int J Epidemiol 1991; 20(3): 736-748.

Jorm AF, Korten AE, Henderson AS. The prevalence of dementia: A quantitative integration of the literature. Acta Psychiat Scand 1987; 76: 465-479.

Juan D, Zhou DH, Li J, et al. A 2-year follow-up study of cigarette smoking and risk of dementia. Eur J Neurology 2004; Apr 11(4): 277-82.

Kaelber CT, Regier DA. Directions in psychiatric epidemiology. Curr Opin Psychiatry 1995; 8(2): 109-115.

Kokmen E, Beard CM, O'Brien PC, et al. Is the incidence of dementing illness changing? A 25-year time trend study in Rochester, Minnesota (1960-1984). Neurology 1993; 43(10): 1887-1892.

Lobo A, Copeland JRM, Dewey M, et al. The prevalence of dementia in the elderly people living in Zaragoza and Liverpool. Psychol Med 1992; 22: 239-243.

Lobo A, Launer LJ, Fratiglioni L, et al. Prevalence of dementia and major subtypes in Europe: A collaborative study of population-based cohorts. Neurology 2000; 54(Supl 5): 4-9.

Lobo A, Saz P, Marcos G, et al. The ZARADEMP Project on the incidence, prevalence and risk factors of dementia (and depression) in the elderly community: I. The context and the objectives. Eur J Psychiatry 2005a; 19(1): 31-39.

Lobo A, Saz P, Marcos G, et al. The ZARADEMP Project on the incidence, prevalence and risk factors of demen- tia (and depression) in the elderly community: II. Methods and first results. Eur J Psychiatry 2005b; 19(1): 40-54.

Lobo A, Saz P, Marcos G, et al. The prevalence of dementia and depression in the elderly community in a Southern European population: the Zaragoza study. Arch Gen Psychiat 1995; 52: 497-506.

Plum AF. Dementia: an approaching epidemic. Nature 1979; 279: 372-373

Pyles RB. The association of herpes simplex virus and Alzheimer's disease: a potential synthesis of genetic and environmental factors. Herpes 2001; 8(3): 64-68.

Rocca WA, Hofman A, Brayne C, et al. Frequency and distribution of Alzheimer's disease in Europe: a collaborative study of 1980-1990 prevalence findings. Ann Neurol 1991; 30: 381-390.

Saz P, Día JL, De-la-Cámara C, et al. Reliability and validity of the Spanish version of the GMS-AGECAT package for the assessment of dementia and cognitive disturbances. Int J Geriatric Psych 1996; 11: 721-728.

Suay L, Ballester F. Review of studies on exposure to aluminum and Alzheimer's disease. Rev Esp Salud Publica 2002; 76(6): 645-658.

Sutker PB, Galina ZH, West JA, Allain AN. Traumainduced weight loss and cognitive deficits among former prisoners of war. J Consult Clin Psychol 1990; 58(3): 323328 .

Address of correspondence:

Dr. Antonio Lobo

Servicio de Psiquiatría

Hospital Clínico Universitario, planta 3

Avda. San Juan Bosco, 15

50009 Zaragoza, SPAIN

e-mail: alobo@unizar.es

SPAIN 
